\title{
EDUCAÇÃO AMBIENTAL NO CURSO DE GRADUAÇÃO EM CIÊNCIAS SOCIOAMBIENTAIS DA UNIVERSIDADE FEDERAL DE MINAS GERAIS: UMA REFLEXÃO SOBRE A AMBIENTALIZAÇÃO NO ENSINO SUPERIOR
}

Ely Bergo de Carvalho ${ }^{1}$ Carolina Quinetti Ribeiro² Luís Otavio Pimenta Cruz ${ }^{3}$

Vitor Meinberg Cunha ${ }^{4}$

Resumo: A legislação brasileira determina a inserção da Educação Ambiental na graduação, mas a ambientalização do ensino superior é um grande desafio. O bacharelado em Ciências Socioambientais da Universidade Federal de Minas Gerais é um caso excepcional para tal inserção, pois é interdisciplinar e voltado para a área ambiental. O objetivo da presente pesquisa é compreender a inserção da Educação Ambiental e a percepção dos discentes e egressos em tal caso, usando questionários e análise documental. Resulta que a Educação Ambiental aparece de forma interdisciplinar e contextualizada, mas desarticulada, já a percepção é variada, do tipo pragmática, conservacionista e histórica.

Palavras-chave: Ciências Socioambientais; Ensino Superior; Educação Ambiental; Ambientalização; Diretrizes Curriculares Nacionais para a Educação Ambiental.

2 Universidade Federal de Minas Gerais. E-mail: carolquinetti@ufmg.br.

${ }^{3}$ Universidade Federal de Minas Gerais: E-mail: lopc@ufmg.br.

4 Universidade Federal de Minas Gerais: E-mail: vitormeinberg@yahoo.com.br. 
Abstract: Brazilian legislation establishes the insertion of environmental education within undergraduate studies, but the environmentalization of higher education is a major challenge. The bachelor's course in Socioenvironmental Science at the Federal University of Minas Gerais is an exceptional case for such an insertion, as the course is interdisciplinary and aimed at the environmental area. The purpose of this research study is to understand how environmental education is included, and the perception of present and former students in this case, using questionnaires and analysis of documents. This study found that environmental education appears in a contextualised and interdisciplinary manner, while perception is varied, yet of the pragmatic, conservationist, and historical type.

Keywords: Socioenvironmental Sciences; Higher Education; Environmental Education; Environmentalisation; National Curriculum Guidelines for Environmental Education.

\section{Introdução}

A Educação Ambiental (EA) como componente essencial e permanente no ensino superior não é apenas uma obrigação legal, mas um imperativo, com a finalidade de contribuir para a formação de graduados com capacidade de agir no mundo, de forma socioambientalmente ética, responsável e politicamente esclarecida.

Uma verdadeira ambientalização dos currículos de graduação implicaria em uma "refundação da educação superior" (LEFF, 1993, p. 22) com: uma Educação Ambiental que supere a racionalidade hegemônica, economicista e que separa humanos e natureza; uma EA que seja capaz de compreender as diferentes racionalidades socioambientalmente enraizadas, de forma a produzir um saber ambiental; e uma transformação não apenas na forma hegemônica de cognição, mas nas formas de ser-no-mundo (LEFF, 2001).

Todavia, a mera inserção da Educação Ambiental, nos termos da lei, nos currículos de graduação, tem sido um desafio difícil de ser atingido. Por isso, o conceito de ambientalização é utilizado aqui em um sentido restrito de cumprir a presença e o papel esperado, oficialmente, da Educação Ambiental, em conformidade com as Diretrizes Curriculares Nacionais para a Educação Ambiental. É extensa a literatura que mostra a fragilidade e dificuldade de ambientalização do ensino superior. Daí a importância dos estudos de caso que ajudem a compreender as diferentes estratégias e limites em cumprir a legislação brasileira sobre o tema.

O curso de graduação em Ciências Socioambientais da Universidade Federal de Minas Gerais (UFMG) é um caso excepcional para entender a relação entre Educação Ambiental e ensino superior, pois trata-se de um curso que tem como escopo, preparar profissionais que atuem, diretamente, em instituições e conflitos de caráter socioambiental, sendo que tem uma estrutura interdisciplinar. Considerando que a interdisciplinaridade da EA é um dos 
principais limites para trabalhar a Educação Ambiental nos cursos disciplinares, nos quais, muitas vezes, o meio ambiente é reduzido aos aspectos próprios de cada graduação, ficando restritos, por exemplo, aos seus aspectos técnicos, biofísicos ou sociais. Esses fatores isolados levam a não compreensão das relações entre as áreas, sendo que o ambiente está justamente nas relações e, dessa forma, o entendimento dos desafios socioambientais tende a ser superficial. Ademais, são raros os cursos de graduação que trabalham diretamente com problemáticas socioambientais, a Geografia e a Ecologia são as grandes exceções. Todavia, como será abordado, a literatura mostra que, mesmo em tais cursos, a Educação Ambiental ainda fica restrita a perspectivas disciplinares. Destarte o curso de Ciências Socioambientais apresenta, em princípio, um contexto muito favorável à Educação Ambiental.

Isso posto, o objetivo da pesquisa é compreender as estratégias formais de inserção da Educação Ambiental, por meio da análise do Projeto Pedagógico do Curso (PPC) e dos programas das disciplinas, bem como compreender a percepção de Educação Ambiental dos discentes e egressos do Curso, por meio de uma abordagem quali-quantitativa.

O curso de Ciências Socioambientais é um bacharelado noturno, criado no âmbito do Programa de Apoio a Planos de Reestruturação e Expansão das Universidades Federais (REUNI). A primeira turma ingressou em 2010, tendo uma entrada anual de 50 alunos. Foi criado a partir da percepção de que faltavam profissionais que atendessem a demanda de pessoal para atuar no terceiro setor, setor público e privado e que conseguissem trabalhar questões sociais, naturais e técnicas de modo integrado. De forma a

[...] transcender os paradigmas transdisciplinares que colonizaram o campo das relações sociedade-natureza - a geografia, a ecologia - para abordar as interrelações da complexidade ambiental interrogando o tempo humano desde diferentes racionalidades culturais. (LEFF, 2001, p. 3).

O objetivo do curso, segundo o PPC, é formar profissionais

[...] capacitados para refletir e intervir, de forma metódica e integrada, sobre os processos contemporâneos que envolvem as relações entre sociedade(s) e ambiente(s), tendo em vista as imbricações de suas dimensões sociais, culturais, econômicas, políticas, espaciais, históricas e ecológicas (UFMG, 2012, p. 18).

curso de Ciências Socioambientais, na época da pesquisa, tinha uma matriz curricular com a participação de 12 departamentos diferentes: Genética, Ecologia e Evolução; Ciência Política; Ciências Econômicas; Direito Público; Engenharia Sanitária e Ambiental; Filosofia; Geologia; História; Medicina 
Preventiva e Social; Antropologia e Arqueologia; Demografia e Sociologia (UFMG, 2012, p. 12). No momento da sua criação, era o único, no país, que oferecia o grau de bacharel em Ciências Socioambientais. Sendo que, há no Brasil uma série de cursos de Ciências Ambientais recentes como o aqui em tela, mas, em geral, tais cursos tiveram sua formação por iniciativas da área de ciências naturais, tendo uma forte presença de disciplinas dessa área em suas grades curriculares. Já o de Ciências Socioambientais teve sua formação originada na Faculdade de Filosofia e Ciências Humanas, acabando por enfatizar disciplinas na área de humanidades em sua grade curricular. Contudo, é um curso efetivamente interdisciplinar, no sentido proposto por Leff (2006, p. 311).

A interdisciplinaridade implica [...] um processo de inter-relação de processos, conhecimentos e práticas que transborda e transcende o campo da pesquisa e do ensino no que se refere estritamente às disciplinas científicas e a suas possíveis articulações. Dessa maneira, o termo interdisciplinaridade vem sendo usado como sinônimo e metáfora de toda interconexão e 'colaboração' entre diversos campos do conhecimento e do saber dentro de projetos que envolvem tanto as diferentes disciplinas acadêmicas, como as práticas não científicas que incluem as instituições e atores sociais diversos.

Nicolescu (1999) traz uma definição mais restrita, pois para ele, a interdisciplinaridade é o diálogo e colaboração entre disciplinas, cada uma abordando o mesmo fenômeno, mas com objetivos disciplinares; já a transdisciplinaridade é a pesquisa integrada de um fenômeno, com o diálogo e articulação de diferentes disciplinas, com objetivo integrado e partindo de uma base de valores e princípios compartilhados, que transcendem o campo científico. Ora, em tal noção stricto sensu, o curso atende, também, a noção de interdisciplinaridade, já a citada concepção de transdisciplinaridade é mais um horizonte a ser alcançado, pois apesar de incluir práticas não científicas, elas não formam uma base unida de valores compartilhados, como se verá adiante.

Há quatro estratégias para buscar a interdisciplinaridade: primeiro, as atividades acadêmicas curriculares, preferencialmente, não são "puramente" disciplinares, ou seja, buscam enfatizar o diálogo de cada disciplina com o "ambiental", por exemplo, não há uma disciplina de "Introdução à Antropologia", mas uma disciplina de "Cultura e Ambiente", não há "Introdução à Economia", mas "Economia e Ecologia"; segundo, há uma grande carga horária de disciplinas que podem ser escolhidas pelos discentes, das 2.400 horas do curso, 800 são em disciplinas optativas e eletivas, dando uma grande margem de manobra para os discentes escolherem, sob supervisão do Colegiado de Curso, um percurso que envolva várias áreas do conhecimento; terceiro, os profissionais que lecionam no curso, preferencialmente, têm como área de pesquisa questões socioambientais, de conservação da biodiversidade à direito ambiental, o que facilita a ênfase interdisciplinar e ambiental das disciplinas; 
quarto, há atividades acadêmicas integradoras, com a participação de professores ou com a abordagem de várias áreas do conhecimento, como é o caso das "Aulas Práticas Integradas de Campo A e B".

Por um lado, a UFMG tem uma estrutura institucional disciplinar, quando se compara com estruturas institucionais e percursos formativos como o da Universidade Federal do ABC, com cursos/bases interdisciplinares de formação, seguido da especialização disciplinar, ou, ainda, de instituições internacionais que permitem uma grande flexibilidade formativa em todo o percurso da graduação. Por outro lado, a UFMG tem um projeto institucional de flexibilização curricular, incorporando, necessariamente, em todos os currículos, a possibilidade ou a obrigação de cursar atividades de áreas diferentes, sendo efetivamente criada a disponibilidade para os discentes cursarem as atividades acadêmicas de outras áreas que não a do seu curso.

Por fim, em uma pesquisa com egressos foi constatado que os dados permitiram afirmar que o "curso de Ciências Socioambientais foi bem-sucedido em formar um profissional de perfil interdisciplinar". Ademais, há uma proximidade profissional com Educação Ambiental, sendo que 10\% dos egressos, que trabalhavam na área de formação, estavam trabalhando na área de educação (CARVALHO; CARMO; HATAKEYAMA, 2019, p. 307, 314).

Isso posto, fica claro porque o curso é um caso excepcional para a presença da Educação Ambiental. Tendo condições favoráveis para tal, entender as estratégias e a percepção dos discentes pode ajudar a iluminar as dificuldades e oportunidades de trabalhar a Educação Ambiental no ensino superior.

\section{Educação Ambiental no ensino superior no Brasil}

No Brasil, a presença da Educação Ambiental no ensino superior é uma obrigação legal, formalmente regulamentada para estar presente de forma articulada e politizada nos currículos de graduação. A Constituição Federal Brasileira de 1988, em seu artigo 225, determina que todos "têm o direito ao meio ambiente ecologicamente equilibrado, bem de uso comum do povo e essencial à sadia qualidade de vida [...]", sendo que, no parágrafo $1^{\circ}$, inciso $\mathrm{VI}$, incumbe ao poder público "promover a Educação Ambiental em todos os níveis de ensino [...]" (BRASIL, 1988). A Lei no 9.795, de 27 de abril de 1999, que institui a Política Nacional de Educação Ambiental define que:

Entende-se por Educação Ambiental os processos por meio dos quais o indivíduo e a coletividade constroem valores sociais, conhecimentos, habilidades, atitudes e competências voltados para a conservação do meio ambiente, bem de uso comum do povo, essencial à sadia qualidade de vida e sua sustentabilidade (BRASIL, Artigo 1ํㅡ, Lei 9.795/1999). 
A lei estabelece a obrigação da EA em seu artigo 10, ao afirmar que a "Educação Ambiental será desenvolvida como uma prática educativa integrada, contínua e permanente em todos os níveis e modalidades do ensino formal." (BRASIL, 1999). Consagrando, em consonância com um longo debate internacional, que a Educação Ambiental não pode ser uma disciplina isolada, mas deve perpassar várias disciplinas. De forma que, no artigo $5^{\circ}$ da citada lei, há a definição do objetivo da EA, como "[...] o desenvolvimento de uma compreensão integrada do meio ambiente em suas múltiplas e complexas relações, envolvendo aspectos ecológicos, psicológicos, legais, políticos, sociais, econômicos, científicos, culturais e éticos" (BRASIL,1999). Confirmando o caráter interdisciplinar e transversal ao determinar que ela "não deve ser implantada como disciplina específica no currículo de ensino" (BRASIL, § 1으, art. 10, Lei ํo 9.795/1999)5.

As Diretrizes Curriculares Nacionais para a Educação Ambiental assumem uma postura forte sobre qual tipo de Educação Ambiental deveria estar presente na educação formal, conforme pode ser visto no caput dos artigos $5^{\circ}$ e 6으, ao definir que "[...] a Educação Ambiental não é atividade neutra, [...] envolve valores, interesses, visões de mundo [...] deve assumir [...] de forma articulada [...] as suas dimensões políticas e pedagógicas" e "deve adotar uma abordagem que considere a interface entre a natureza, a sociocultural, a produção, o trabalho, o consumo, superando a visão despolitizada [...] (BRASIL, 2012).

Apesar de postular que a EA é uma "dimensão da educação", regulamenta, pragmaticamente, que:

Art. 16. A inserção dos conhecimentos concernentes à Educação Ambiental nos currículos da Educação Básica e da Educação Superior pode ocorrer:

I - pela transversalidade, mediante temas relacionados com o meio ambiente e a sustentabilidade socioambiental;

II - como conteúdo dos componentes já constantes do currículo;

III - pela combinação de transversalidade e de tratamento nos componentes curriculares (BRASIL, 2012).

O Ministério da Educação faz o reconhecimento e a avaliação periódica de todos os cursos de graduação, tendo em consideração tal obrigação legal da presença da EA (BRASIL, Artigo 24, 2012). Entretanto, as pesquisas têm

\footnotetext{
${ }^{5}$ Ressalvado nos casos previstos no parágrafo segundo: "Nos cursos de pós-graduação, extensão e nas áreas voltadas ao aspecto metodológico da Educação Ambiental, quando se fizer necessário, é facultada a criação de disciplina específica." (BRASIL, Lei no 9.795/1999).
} 
demonstrado que - apesar da legislação em vigor no país apontar a Educação Ambiental para uma direção integrada - na prática, a introdução da EA tem sido inserida de forma pontual, com concepções simplificadoras ou, de forma superficial, apenas para atender a avaliação. A percepção dos discentes acompanha tal estado de coisas, mesmo em curso que historicamente identifica-se com questões ambientais, nos quais esperava-se uma percepção mais crítica e complexa.

Os estudos de caso corroboram tal cenário. Por exemplo, Veiga et al. (2013, p. 214) fazem um estudo nos cursos de Administração, Pedagogia, História, Turismo, Contabilidade e Direito de uma instituição de ensino superior em Teresina, Piauí, e verificaram, por meio de questionário, que a Educação Ambiental é tratada de forma pontual e não articulada nas disciplinas das graduações pesquisadas. A percepção dos docentes é a de que a EA tem grande importância, sendo que $85,7 \%$ dos docentes afirmaram que podem trabalhar a "questão ambiental" em suas disciplinas, apesar de considerarem que, na prática, há poucas disciplinas relacionadas à temática.

Thomaz e Camargo (2007), utilizando questionário, encontraram a defesa da EA de forma interdisciplinar, mas também, profissionais que propugnam sua disciplinarização no ensino superior. De qualquer forma, no caso, a EA não é integrada nos currículos. Afirmam que os depoimentos

[..] possibilitou-nos constatar que as Instituições de Ensino Superior não têm efetivado mudanças nas estruturas curriculares e/ou institucionais com relação ao desenvolvimento da EA; que o desenvolvimento da EA no Ensino Superior, quando ocorre, é isolado, em geral em áreas biológicas; e que conteúdos sobre EA estão na dependência de profissionais capacitados para essa finalidade (THOMAZ; CAMARGO, 2007, p. 315).

De forma semelhante, Souza et al. (2017, p. 3455), ao pesquisar professores e técnicos de um curso de Química em uma universidade pública de Minas Gerais, concluem que os docentes e técnicos pouco conhecem a legislação vigente sobre Educação Ambiental, sendo pouco desenvolvida nas disciplinas dos professores pesquisados, pois a EA é reconhecida apenas nas temáticas ligadas ao manejo de resíduos e rejeitos químicos dos laboratórios e "a EA ainda é abordada de forma naturalista e muito distanciada da abordagem política e social", ou seja, "remete a questões pontuais, em aspectos técnicos ligados ao curso, sem contextos mais amplo, logo, acrítica".

Lopes e Zancul (2012, p. 13) fazem coro ao afirmar que a EA, nas licenciaturas, é praticamente incipiente. Ao analisar os programas das disciplinas do curso de Biologia, nas universidades estaduais paulistas, identificaram que as disciplinas voltadas para a EA se restringiam aos aspectos 
biológicos, e concluíram que "os cursos analisados estão longe de atender às recomendações [...] no que se refere à inserção da dimensão ambiental nos currículos de formação de professores".

Silva et al. (2016) ao estudarem os programas de 62 disciplinas consideradas pelos coordenadores de curso como "ambientalmente orientadas", da Pontifícia Universidade Católica do Rio Grande do Sul PUCRS, afirmam que 16 eram fracamente ambientalizadas, 24 não foram consideradas ambientalizadas pelas autoras e 22 foram consideradas fortemente ambientalizadas, tendo como critério central para a avaliação, que o programa seja voltado para formar sujeitos "socioambientalmente responsáveis” (SILVA; WACHHOLZ; CARVALHO, 2016, p. 218).

Assim, no Brasil há experiências relatadas, nas quais as pessoas estão preocupadas em "colocar a questão ambiental em uma perspectiva histórica e complexa, procurando não apenas passar informações sobre o 'meio ambiente', mas também, construir uma nova racionalidade ambiental" (CARVALHO; FONSECA, 2016, p. 109). Contudo, os estudos de caso indicam, geralmente, a presença do que Brügger (2004) denominou "adestramento ambiental", no qual o conteúdo atribuído à EA é reduzido ao ensino de aspectos fragmentados, em geral, vindos das ciências naturais, o que apenas contribui para reforçar a lógica de pensamento que gerou os problemas ambientais atuais, lógica disjuntiva, na qual o mundo natural e o social são pensados de forma desarticulada. Um treinamento, que se aproxima de um adestramento,

[...]ou seja, trata-se de um tipo de instrução onde as pessoas são levadas a executar determinadas funções e tarefas, identificadas com um padrão utilitário-racional de pensamento e ação que se restringe a um universo unidimensional [...]. (BRÜGGER, 2004, p. 85).

Os estudos que abordam as percepções dos discentes, permitem avaliar o resultado do processo de ambientalização no ensino de graduação. Reigota (1995, p. 76), um pioneiro no Brasil no estudo de representações sociais sobre o meio ambiente, em pesquisa realizada em 1991, já indicava que os alunos que frequentavam o curso sobre $E A$, por ele ministrado, não tinham elementos "suficientes para reconhecer no meio ambiente um conteúdo existencial e conceitual multifacetado", predominando uma concepção naturalista, em que os aspectos biofísicos são tomados como o objeto a ser estudado. A situação, infelizmente, não obteve mudanças significativas desde então.

Por exemplo, Pase et al. (2014), estudando alunos de Administração em Santa Maria, no Rio Grande do Sul, concluíram que os alunos entrevistados não perceberam as ações de Educação Ambiental no curso. Afirmam, ainda, que os discentes estão pouco preocupados em desenvolver ações para a "preservação do meio ambiente". 
No curso de Engenharia da Universidade de São Paulo, estudado por Romão et al. (2020), a Educação Ambiental basicamente não é percebida pelos alunos no curso, sendo identificada como algo que ocorre, exclusivamente, no ensino básico.

Acompanhando tal abordagem, em estudos de casos feitos em cinco universidades brasileiras públicas e privadas, Braga et al. (2018) postulam em seus resultados, "[...] que a percepção ambiental do universitário tem foco na reciclagem, economia de água [...] fora estas questões, os constructos formadores da percepção ambiental, não se mostraram efetivos para a formação da consciência ambiental" (BRAGA et al., 2018, p.1077).

A percepção dos discentes em cursos que, tradicionalmente, têm mais enfoque em Educação Ambiental, também, apresenta um cenário limitado.

Estudo feito em Piracicaba, São Paulo, com egressos e alunos concluintes de licenciatura em Ciências Biológicas, corroboram que a Educação Ambiental é abordada no ensino superior, geralmente, de forma pontual. No caso, com uma abordagem naturalista, a ponto de ser confundida com a disciplina de Ecologia. Sendo que Guimarães e Inforsato (2012), postulam que:

Os resultados indicam que o Professor de Biologia ainda necessita de uma formação mais crítica em relação a Educação Ambiental e que, numa perspectiva complexa, essa formação necessita ser tratada de forma mais rigorosa na universidade [...] para que os profissionais formados possam atuar, efetivamente, na formação cidadã para uma sociedade mais sustentável (GUIMARÃES; INFORSATO, 2012, p. 737).

Chegando a resultados bastante semelhantes, Araújo (2004), ao estudar a licenciatura em Biologia da Universidade de São Paulo, apesar de identificar avanços na "formação ambiental", ainda fica a "formação pedagógica no âmbito da intelectualidade e da preparação para transmitir conceitos, sem considerar as transformações historicamente construídas e a necessidade de preparar o futuro professor para enfrentar" as transformações exigidas na formação de professores (ARAÚJO, 2004, p. 77).

Borges e Oliveira (2018) também analisaram os estudantes de Biologia, mas da Faculdade de Caldas Novas, fazendo uma pesquisa quali-quantitativa, com sujeitos, no ingresso e na conclusão do curso de Biologia. Segundo os autores, "as atitudes de preservação e conservação" são mais perceptíveis entre os egressos, que tiveram "mudanças significativas de comportamento". Mesmo que as práticas pedagógicas utilizadas durante a graduação, na percepção dos discentes, não tenham sido "suficientes"' para habilitá-los a aplicar uma significativa Educação Ambiental” (BORGES; OLIVEIRA, 2018, p. 79). 
A dissertação de mestrado de Souza (2011) trata dos cursos de graduação nas instituições públicas do Rio de Janeiro que tinham o adjetivo ambiental, como Ciência Ambiental, Geografia Marinha e Ambiental, entre outras. Ao realizar entrevistas com os coordenadores e analisando os planos de estudo constatou que há, nos cursos, uma concepção "naturalista e antropocêntrica" de meio ambiente, de forma que a EA aparece como o ensino de questões técnicas inerentes às disciplinas, ou seja, acrítica, posto que sem contextualização ou uma abordagem interdisciplinar.

Em termos internacionais, as pesquisas mostram um quadro semelhante, pelo menos para a América Latina. Eschenhagen Durán (2016) argumenta que o México e o Brasil são os países, no subcontinente, que mais têm aportes na área de Educação Ambiental, todavia afirma que:

Muito se fala sobre a importância da Educação Ambiental no ensino superior e, na América Latina, consolidaram-se redes universitárias que reivindicam a importância da Educação Ambiental nas suas instituições. Ao mesmo tempo, observa-se que muitos dos esforços das universidades têm sido centrado e objetivando mais a gestão ambiental adequada do campus e na pesquisa de problemas ambientais específicos, o que, sem dúvida, é importante como um exemplo para a sociedade e para fornecer soluções para os problemas ambientais que realmente existem; No entanto, essa abordagem da Educação Ambiental perdeu de vista um dos objetivos centrais da universidade: a formação de futuros profissionais e tomadores de decisão (ESCHENHAGEN DURÁN, 2016, p.12, grifo nosso, tradução nossa).

Dessa forma, o diagnóstico é de uma Educação Ambiental no ensino superior brasileiro, geralmente, desarticulada, pontual, longe de conseguir alcançar uma abordagem interdisciplinar e seu conteúdo é reduzido a aspectos disciplinares, na qual questões ambientais que emergem da relação entre ambientes e sociedades não são compreendidas adequadamente, posto que reduzidas a uma de suas dimensões.

\section{Metodologia}

A pesquisa foi idealizada a partir de uma disciplina optativa ministrada no segundo semestre de 2018, no curso de Ciências Socioambientais. Trata-se de uma pesquisa quali-quantitativa, pois o questionário visou tanto a coleta de dados para produção de informação, quanto buscou compreender a parte subjetiva apresentada nas respostas. $\mathrm{Na}$ pesquisa documental foram analisados o Projeto Pedagógico do Curso, bem como os programas de disciplinas obrigatórias. Utilizando uma análise de conteúdo, que aborda 
palavras-chaves e o contexto geral de interpretação dos textos e questionários (GIL, 2008; SÁ-SILVA; ALMEIDA; GUINDANE, 2009).

Para efetivar a pesquisa, foi elaborado um questionário on-line com o objetivo de avaliar o entendimento dos graduandos e graduados a respeito da Educação Ambiental no curso de Ciências Socioambientais. O questionário foi desenvolvido na plataforma Formulários Google, sendo composto por 11 perguntas, abertas e fechadas, sem identificação do informante. A coleta de dados ocorreu, no período de novembro de 2018 a julho 2019, mediante disponibilização do formulário via e-mails e divulgação nas mídias sociais (Facebook e WhatsApp).

O curso de Ciências Socioambientais, segundo dados do Colegiado de Graduação, contava com 221 alunos matriculados e 120 egressos até junho de 2019. Optou-se por excluir aqueles que tivessem apenas o primeiro ano, pois os calouros tiveram oportunidade de travar contato com pouquíssimas disciplinas.

Desse modo, o universo de informantes possíveis ficou estabelecido em 285 indivíduos, ou seja, 120 egressos, mais o total de 221 estudantes matriculados em junho de 2019, subtraído os 56 discentes matriculados, que ingressaram em 2019. Do universo de 285 indivíduos obteve-se 56 questionários respondidos, logo uma amostra de 19,6\%.

\section{Educação Ambiental no curso de Ciências Socioambientais}

No caso da UFMG, quase vinte anos depois da implementação da Lei no 9.795/1999, a ambientalização ainda constava como um objetivo a ser alcançado. O Plano de Desenvolvimento Institucional (PDI), da UFMG, para 2018-2023, propõe, como um dos objetivos, garantir "[...] uma presença significativa da temática ambiental no universo do ensino de Graduação [...]", sendo garantido que os egressos "sejam cidadãos bem informados sobre tal temática, e que exista a possibilidade, em todos os currículos, de que o estudante obtenha um aprofundamento de estudos sobre o tema, em conexão com seu campo de formação". Além disso, uma de suas ações é "garantir a presença de no mínimo uma disciplina voltada para a questão ambiental em todos os currículos de Graduação" (UFMG, 2018, p. 183). No caso do curso de Ciências Socioambientais, as disciplinas voltadas para a "questão ambiental" já são a regra e não uma inserção pontual.

O Projeto Pedagógico do Curso de Ciências Socioambientais está pautado na superação da fragmentação disciplinar, formando um profissional com perfil interdisciplinar e com um horizonte transdisciplinar:

Este projeto salienta [...] a necessidade de se estabelecer um espaço de reflexão crítico às posturas hegemônicas e homogeneizadoras que subsumem os complexos processos 
sociais e os diversos sujeitos neles envolvidos em uma metafísica do ambiente, reduzindo-o, por esta via, a um objeto material, uno e quantificável, passível, portanto, de inscrição numa causa universal sob forte direcionamento economicista. Com efeito, em muitos contextos e conjunturas, o meio ambiente é atravessado por conflitos sociais entre sujeitos que sustentam projetos distintos de sociedade e, numa perspectiva política, possuem posições assimétricas. A diversidade biológica pensada de forma indissociada da diversidade dos modos de vida nas sociedades humanas requer um conhecimento socioambiental que tenha como horizonte uma meta transdisciplinar e além - incorporando também os saberes não disciplinares numa perspectiva complexa, expressa seu compromisso com a pluralidade, o pensamento crítico e a equidade ambiental (UFMG, 2012, p. 21).

Todavia, o PPC de Ciências Socioambientais não trabalha diretamente o conceito de Educação Ambiental6. Talvez, por pressupor que a EA está contemplada organicamente dentro do escopo do curso, mas a inexistência de uma menção direta da EA nas competências profissional dos egressos indica, no mínimo, que não houve uma articulação da preocupação com a EA na formalização do curso.

Para avaliar a abrangência da EA na matriz curricular, buscou-se os programas das disciplinas obrigatórias da graduação, para que fosse realizada a análise em cada um destes programas.

$\mathrm{Na}$ análise de 25 programas das disciplinas obrigatórias ${ }^{7}$, em um primeiro momento, buscando o termo Educação Ambiental ou similar, concluiuse que não aparecem em nenhum dos programas.

Contudo, quando se procura a concepção ampla de EA, tal como definida pela Lei oㅡ 9.795/1999, em todos os conteúdos programáticos, foi possível identificar elementos de EA, ora dentro de propostas mais técnica, com $16 \%$, ora mais da dimensão natural, com $24 \%$ e ora mais ligadas a noção de conflitos socioambientais e de dimensão política, com $60 \%$.

De forma semelhante, em todas as disciplinas, os discentes e egressos identificaram conteúdo de Educação Ambiental, apesar de apresentarem graus muito variados (Gráfico 1). Por exemplo, a disciplina de "Conservação da Biodiversidade" ficou em primeiro lugar. No programa dessa disciplina, a proposta é que os alunos tenham aprendizado em ecologia, manejo de recursos naturais, ameaças à biodiversidade, aulas práticas, tendo o contato diretamente com o meio externo à sala de aula, abordando a interação entre os

\footnotetext{
${ }^{6}$ Um novo PPC foi aprovado em dezembro de 2019, todavia, optou-se em trabalhar com o PPC de 2012, pois era o que estava vigente na época da coleta de dados da pesquisa.

${ }^{7}$ Não incluindo, pois não foram analisadas, as disciplinas Estágio Curricular, Trabalho de Conclusão de Curso I e II.
} 
humanos e a natureza, seja de forma positiva ou negativa. Outro exemplo, é a disciplina que ficou em segundo lugar, "História e Ambiente", com um programa que tem como elementos, entender as interações e diferentes concepções de natureza e as transformações do meio ambiente, a partir da ação antrópica ao longo da história, desconstruindo a ideia de um ser humano que está acima da natureza.

Destarte, em todas as disciplinas há aqueles que identificaram elementos de Educação Ambiental:

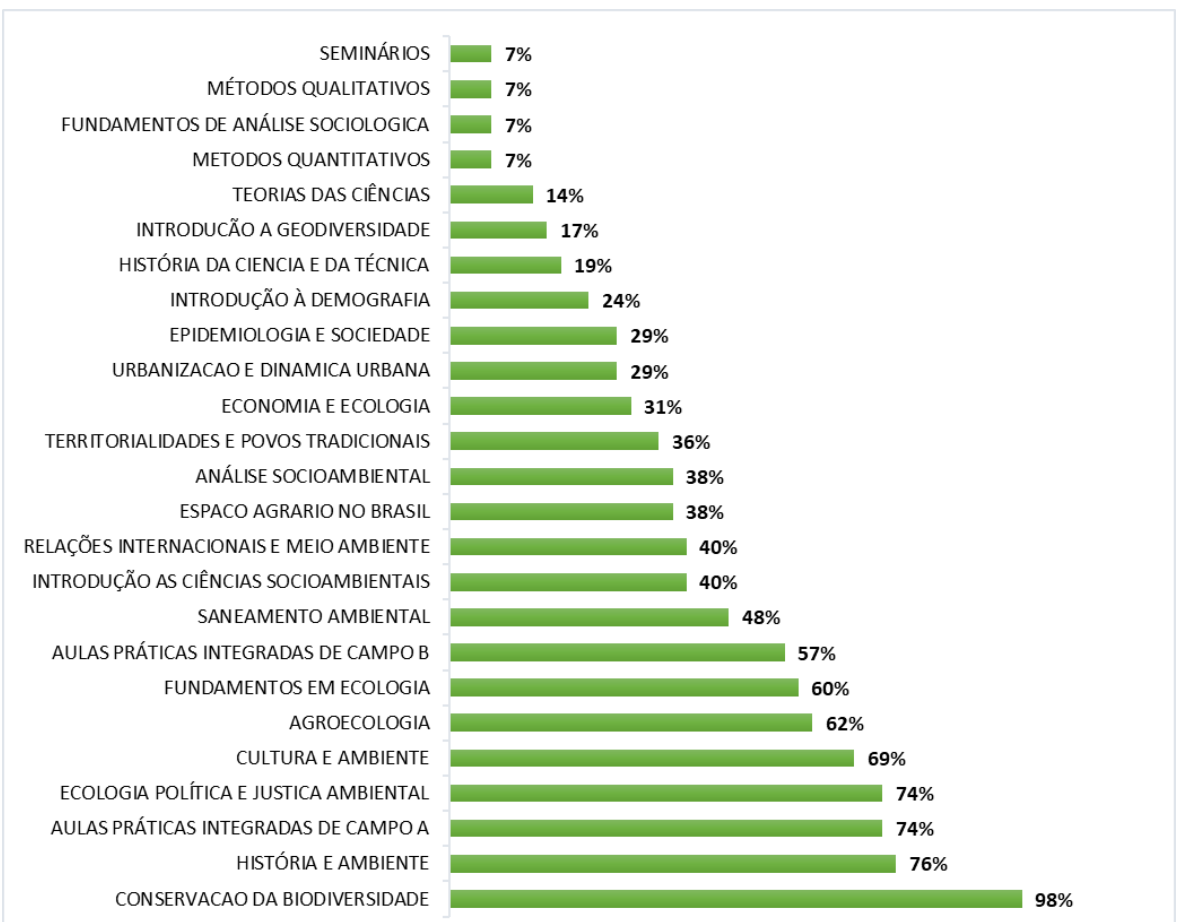

Gráfico 1: Presença da Educação Ambiental nas disciplinas obrigatórias de Ciências Socioambientais, na percepção de egressos e discentes.

Fonte: Elaborado pelo autor (2019).

Assim, em maior ou menor grau, os discentes identificaram a EA nas disciplinas obrigatórias do curso. Ademais, 32\% dos que responderam aos questionários, conseguiram nomear, pelo menos, uma disciplina optativa com abordagem de EA e $21 \%$ conseguiram nomear, pelo menos, uma disciplina com abordagem de EA entre as disciplinas eletivas (fora da matriz curricular). Vale salientar que para as questões abertas, lembrar e nomear é mais difícil que escolher em uma lista de disciplinas obrigatórias, que já estava disponível no questionário. Ou seja, na percepção dos sujeitos abordados, a EA não está presente apenas nas disciplinas obrigatórias do bacharelado.

Pode-se inferir que o PPC de Ciências Socioambientais atende ao que é definido pela legislação aplicável, bem como trata interdisciplinarmente a Educação Ambiental, como por exemplo, em atividades acadêmicas 
interdisciplinares, como na disciplina "Aulas Práticas Integradas de Campo A", ministrada, simultaneamente, por três professores de áreas diferentes, que ficou em terceiro lugar na percepção da presença de EA.

Salienta-se que os programas das disciplinas não compartilham a mesma perspectiva de Educação Ambiental, pois alguns programas abordam mais os conflitos socioambientais e a dimensão política, outros a dimensão natural, abordando a preservação da natureza e outros enfatizam os aspectos técnicos e pragmáticos de solução de problemas ambientais.

\section{A percepção de Educação Ambiental dos discentes e egressos}

$\mathrm{Na}$ busca por entender a concepção de Educação Ambiental foi feita a pergunta literal: o que você entende por Educação Ambiental? Buscou-se fazer uma classificação do tipo de EA que aparecia nas respostas, mesmo considerando que toda forma de classificação é um "ato de violência" contra a diversidade do mundo.

Layrargues e Lima (2014) propõem três macrotendências políticopedagógicas de EA: a "conservacionista", voltada para a proteção da natureza; a "pragmática", ligada as soluções de problemas ambientais, pautadas na tecnologia e nos mecanismos de mercado, que valoram economicamente a natureza enquanto recursos naturais; e a "crítica", uma corrente voltada para a justiça ambiental e a compreensão múltipla e conflitiva das questões ambientais. Carvalho e Muhle (2017) mostram, de forma assertiva, os problemas desse tipo de classificação.

O problema é que, ao mesmo tempo, estas tentativas de organizar a dispersão dos conceitos e das abordagens da EA muito facilmente terminam demarcando preferências e hierarquizando as muitas possibilidades das formas de fazer e entender as educações ambientais. Para não dizer do risco de moralizar a questão epistêmica, criando um gradiente que vai das boas e desejáveis até as más ou indesejáveis educações ambientais (CARVALHO; MUHLE, 2017, p. 169).

A proposta de Layrargues e Lima (2014) é, antes de tudo, uma defesa da Educação Ambiental "crítica", que corresponde a uma idealização de um dado tipo de EA, desvalorizando todas as outras propostas. A citada classificação é um instrumento de intervenção política no campo da EA e, enquanto instrumento de luta política, é plenamente legítimo, mas incapaz de valorizar e compreender a diversidade de propostas e perspectivas presente no campo da EA.

Todavia, classificar é, também, uma forma didática de abordar a diversidade de propostas presentes no campo, por este motivo, tomar-se-á 
esse rumo, apenas fazendo as advertências dos limites e armadilhas da classificação utilizada. Desta forma:

a) as respostas com um teor voltado para a "Natureza", foram classificadas como conservacionista, por exemplo, a resposta "Educação que valorize a convivência entre o ser humano e a natureza", obteve $43 \%$ das respostas;

b) as respostas voltadas mais para a "Razão", com erre maiúsculo, indicando uma perspectiva unidimensional, foram classificadas como "pragmáticas", por exemplo: "Visa a conscientização social quanto ao uso de recursos naturais, quanto a possibilidade do reaproveitamento e reuso de bens, bem como a reflexão quanto ao consumo além das necessidades básicas dos indivíduos, ou seja, a relação do homem com o ambiente", ficou com $21 \%$ das respostas classificadas em tal perspectiva;

c) as respostas com teor voltado para a "História", da co-construção de ambientes e sociedades, foram classificadas como "críticas", por exemplo, "Troca de saberes horizontalizada, com base nos conhecimentos cotidianos e locais de cada participante, e que ajude na construção de discernimento crítico em relação a questões socioambientais em nível local e global", obteve $29 \%$ das respostas.

Sendo que, para 7\% não foi possível classificar, pois as respostas foram demasiadamente lacunares. O Gráfico 2 sintetiza essa classificação.

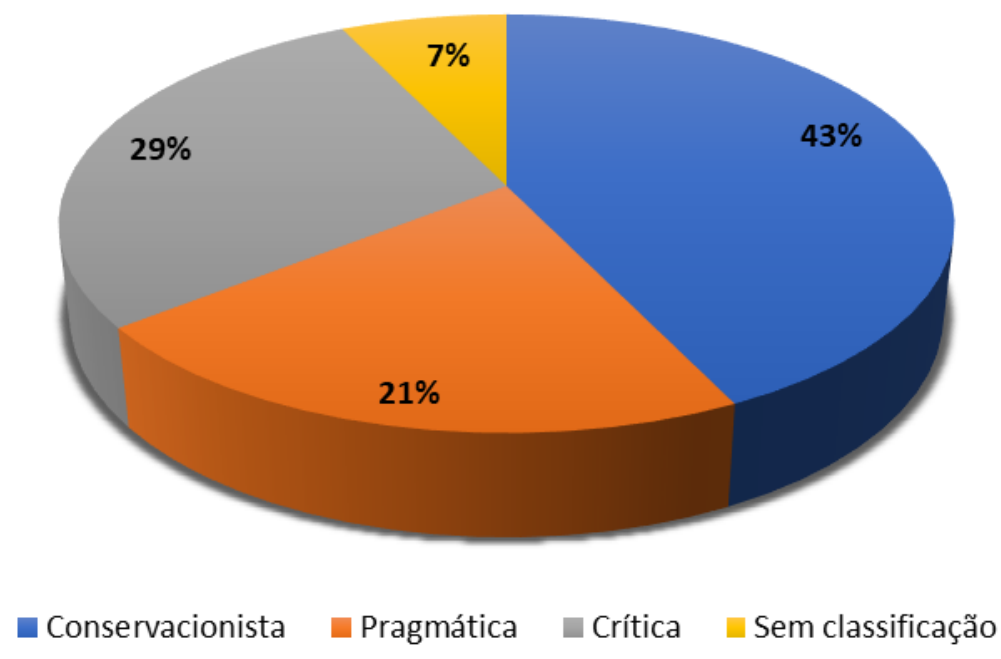

Gráfico 2: Classificação das respostas, de discentes e egressos do curso de Ciências Socioambientais, sobre o que é Educação Ambiental;

Fonte: Elaborado pelo autor (2019).

Apesar de o PPC defender um perfil que poderia ser classificado como "crítico", há uma forte presença da perspectiva "conservacionista" e "pragmática". 
O questionário apresentava outra questão em que os discentes e egressos deveriam responder quais das palavras-chaves correspondiam a concepção de EA presente no curso de Ciências Socioambientais. As palavras "natureza, preservação, alfabetização ecológica e relativização do antropocentrismo" receberam $41 \%$ dos votos; para "razão, solução, desenvolvimento sustentável e consumo sustentável", foram $13 \%$; e para "transformadora, popular, emancipatória e dialógica", teve 46\%, o maior percentual (Gráfico 3).

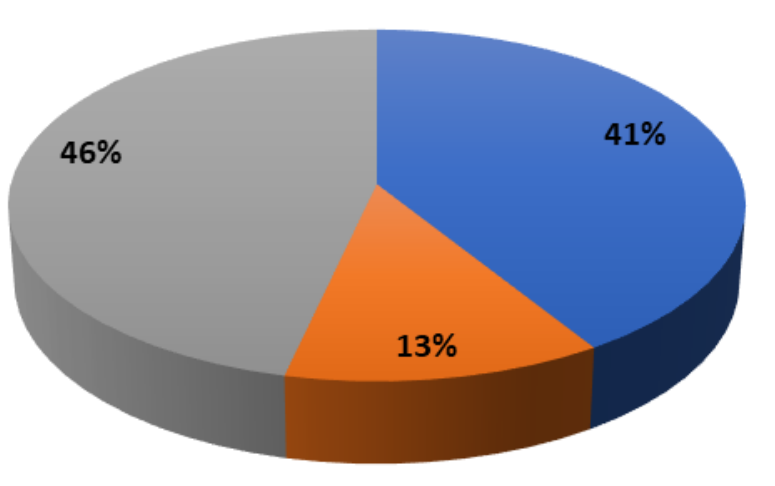

Natureza, preservação, alfabetização ecológica e relativização do antropocentrismo.

- Razão, solução, desenvolvimento sustentável e consumo sustentável.

- Transformadora, popular,emancipatória e dialógica.

Gráfico 3: Termos que melhor identificam a abordagem de Educação Ambiental no curso de Ciências Socioambientais, segundo discentes e egressos.

Fonte: Elaborado pelo autor (2019).

No Gráfico 3, tal como no Gráfico 2, apesar de o PPC fazer uma defesa de uma postura voltada para a justiça ambiental e a transformação radical do status quo, a percepção da EA mais ligada a "Natureza" foi expressiva, com $41 \%$, e uma postura mais pragmática não deixou de estar presente, com $13 \%$. A hipótese explicativa mais plausível é a de que essa divisão acompanha a diversidade de posições presentes nos programas das disciplinas, pois cada área do conhecimento tende a abordar a Educação Ambiental com uma dada ênfase: na área das ciências naturais tendem a ser mais "conservacionistas"; na área das ciências aplicadas tendem a ser mais "pragmáticas"; e na área das humanas tendem a ser mais "críticas", ou, talvez, fosse melhor utilizar o termo, "História" ou "histórica", ao invés de "crítica", pois tendem a apostar em projetos de futuro alternativos, mais radicais na transformação das relações de poder atualmente hegemônicas e no entendimento dos processos construtivos dos ambientes e das sociedades.

Outro elemento que a pesquisa buscou compreender foi o interesse pessoal na Educação Ambiental (Gráfico 4). 


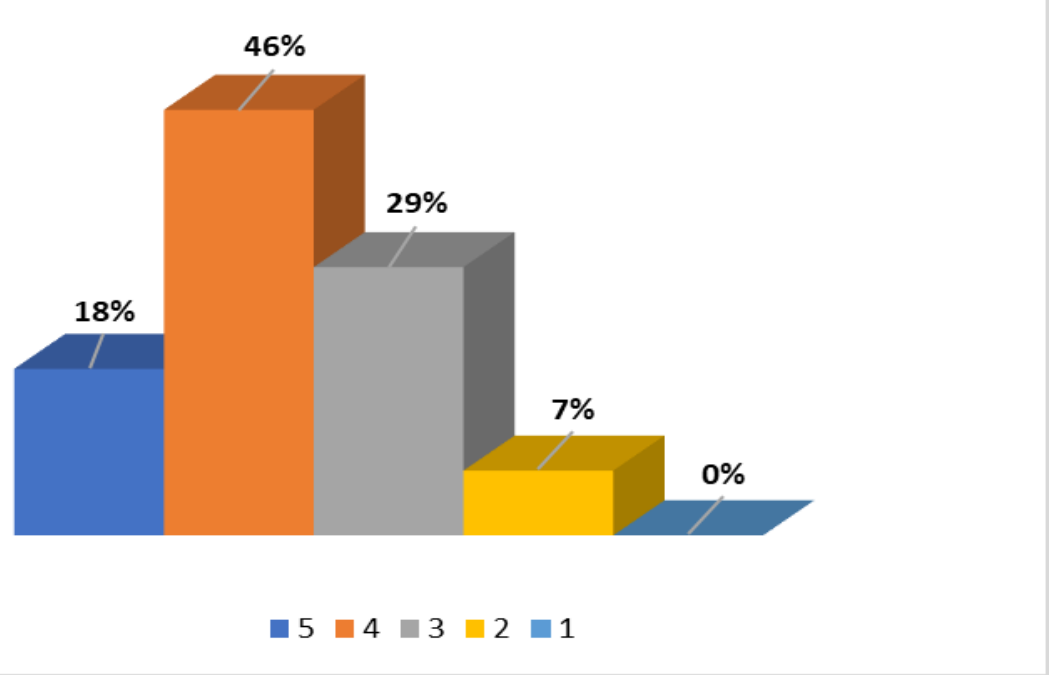

Gráfico 4: Grau de interesse por Educação Ambiental dos egressos e discentes do curso de Ciências Socioambientais.

Fonte: Elaborado pelo autor $(20 ; 19)$.

Sendo (5) o número que expressa maior interesse e (1) o número que expressa o menor interesse, obteve-se que a maior fração das respostas está para o grau "alto" (4), 46\%; seguido pelo grau "médio" (3), com 29\%; grau "extremo" (5), com 18\%; e grau "pouco" (2), com 7\%. É importante evidenciar que não houve a escolha da opção mínima (1), ou seja, todos aqueles que responderam têm interesse por Educação Ambiental.

Os cientistas socioambientais se reconhecem na Educação Ambiental, o que indica o fato de zero por cento apontarem o menor grau e $64 \%$ elevado interesse (Gráfico 5).

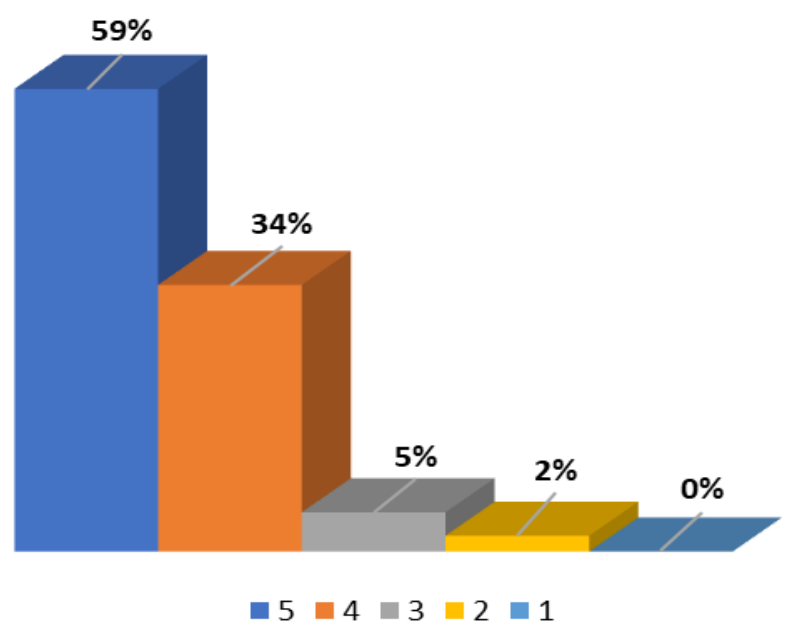

Gráfico 5: Importância atribuída à Educação Ambiental no curso de Ciências Socioambientais, pelos egressos e discentes.

Fonte: Elaborado pelo autor (2019).

Revbea, São Paulo, V. 17, № 1: 458-479, 2022. 
Aos alunos e ex-alunos foi perguntado qual o grau de importância da EA no curso de Ciências Socioambientais. A maioria, 59\% considerou o grau máximo (5) de importância da Educação Ambiental, seguido pela opção (4), com $34 \%$. As opções (3) e (2) obtiveram somente $5 \%$ e $2 \%$, respectivamente. Nota-se que não houve escolha da opção (1), podendo ser inferido que a EA é algo indispensável, na percepção dos alunos e egressos, pois a soma das respostas 5 e 4 representaram $93 \%$ do total.

Os informantes apresentaram uma clara distinção entre o que é importante para o curso de Ciências Socioambientais e seus interesses pessoais. No gráfico sobre o interesse pessoal em Educação Ambiental, 18\% afirmaram (5) ter "extremo" interesse e 46\% "alto" (4) interesse, portanto, são $64 \%$ com grande interesse pessoal; enquanto $93 \%$ consideraram o tema de grande relevância para o curso. O que reforça o argumento que, para além do interesse pessoal, a percepção é a de que a EA é fundamental para o curso de Ciências Socioambientais.

Por fim, a questão que buscou identificar se, na percepção dos discentes e egressos, a EA deve ser uma disciplina ou estar presente apenas nas disciplinas já existentes no currículo (Gráfico 6).

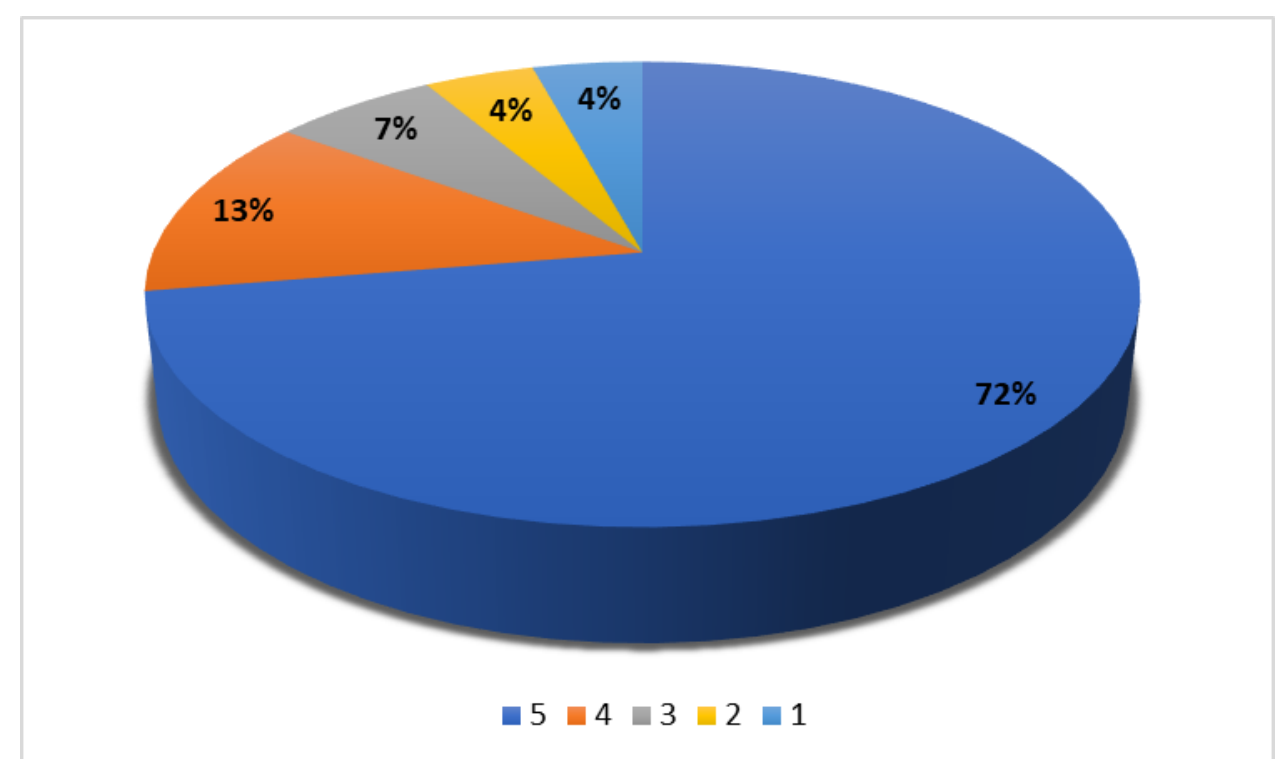

Gráfico 6: Grau de importância atribuída à criação de uma disciplina de Educação Ambiental, por discentes e egressos do curso de Ciências Socioambientais.

Fonte: Elaborado pelo autor (2019).

Apesar do caráter interdisciplinar do curso, a esmagadora maioria acredita, grau (5), na inclusão de uma disciplina específica de EA, com $72 \%$, somado aos que indicaram (4) e (3) tem-se 92\% de "demanda" por uma disciplina específica, e apenas $4 \%$ consideraram o grau (2) e o mesmo ocorreu para o (1). 
Neste ponto, uma consideração importante para compreender a demanda por uma disciplina específica é, justamente, o fato de que uma das atividades em que os egressos podem atuar é na área de Educação Ambiental, mesmo sendo um bacharelado, a EA não escolar é um campo amplo de trabalho, assim, os discentes demandam uma discussão mais verticalizada sobre os debates teóricos e metodológicos da Educação Ambiental, pois, talvez, estejam pensando nesse tipo específico de atuação profissional. O que levanta uma questão polêmica, que vai além do objetivo da pesquisa, qual seja: Seria necessário uma disciplina específica de EA para as graduações em que os profissionais trabalharão diretamente com Educação Ambiental?

\section{Considerações finais}

Como suposto inicialmente, a EA está presente no curso de Ciências Socioambientais de forma orgânica. Diferenciando-o da ausência ou da EA presente de forma pontual ou, ainda, redutível ao conteúdo de uma ou outra disciplina, em uma simplificação da complexidade ambiental.

Apesar de o PPC apontar para uma abordagem ambiental voltada para a justiça ambiental e para os conflitos socioambientais, tanto os programas das disciplinas como a percepção de EA dos discentes e egressos do curso apresentaram uma variedade de perspectivas políticas e propostas de EA. Para compreender tal fato deve ser levado em conta a força que às áreas disciplinares têm no condicionamento do tipo de Educação Ambiental, com uma variedade de abordagens e pressupostos que, seguramente, não podem ser contidos em classificações estanques. Sendo que, tal fato pode ser entendido como um aspecto positivo, da presença de uma variedade de propostas político-pedagógicas; mas também, pode ser entendido de forma negativa, como um indicativo da falta de articulação e/ou, ainda, dos limites da interdisciplinaridade praticada, ou melhor, que o curso não chega a ter uma abordagem transdisciplinar, na qual há um conjunto comum de valores e pressupostos compartilhados.

Seguramente um aspecto limitante no que se refere a EA é a falta de articulação das atividades de EA presentes no curso, por exemplo, o PPC não apresenta uma proposta explícita e específica, sendo que, frequentemente, os discentes declaram não estarem preparados para atuar com EA, tal como ocorre com licenciados em Ciências Biológicas, como já citado. Ademais, apesar de a EA estar presente nas disciplinas, os discentes demandam por uma disciplina específica de EA.

Enquanto um caso excepcional para a ambientalização dos cursos de graduação, o bacharelado em Ciências Socioambientais, em seus pontos fortes, como a interdisciplinaridade e a presença da EA nos programas, permite questionar até que ponto são necessárias mudanças profundas para que um curso apresente, de forma integrada e contextualizada, a Educação Ambiental, uma vez que é um curso voltado para a interdisciplinaridade e a problemática 
ambiental; em seus pontos fracos, como a falta de uma articulação da EA, a demanda por uma disciplina específica de EA e os limites da interdisciplinaridade praticada, apontam que, para uma verdadeira ambientalização, seria necessária uma "refundação da educação superior" (LEFF, 1993, p. 22). Aporias que o estudo de caso não pretende solucionar, mas pode explicitá-las.

De qualquer forma, o caso aqui estudado é útil para refletir sobre oportunidades e dificuldades da implantação das, já citadas, Diretrizes Curriculares Nacionais para a Educação Ambiental, que postulam uma EA "integrada e interdisciplinar" e que "deve adotar uma abordagem" que leve em conta "a interface entre a natureza, a sociocultura, a produção, o trabalho, o consumo, superando a visão despolitizada, acrítica, ingênua e naturalista, ainda muito presente na prática pedagógica das instituições de ensino"

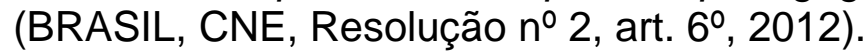

\section{Referências}

ARAÚJO, M.I.O. A universidade e a formação de professores para a Educação Ambiental. Revista Brasileira de Educação Ambiental, Brasília, n. 0, p. 7178, nov. 2004.

BORGES, R.L.; OLIVEIRA, R.V.R. Percepção Ambiental no Ensino Superior: Estudo de Caso no Curso de Ciências Biológicas. São Paulo: Novas Edições Acadêmicas, 2018. 90 p.

BRAGA, W.R.O.; MORAES, N.R.; BAPTISTA, R.D.; PUTTI, F.F.; BRAGA JÚNIOR, S.S. A construção da percepção ambiental de estudantes universitários brasileiros. Revista Observatório, Tocantins, v. 4, n. 3, p. 10761106, abr. 2018.

BRASIL. Constituição da República Federativa do Brasil (1988). Brasília, DF: Senado Federal: Centro Gráfico, 1988.

BRASIL. Lei no. 9.795, 27 de abril de 1999. Dispõe sobre a Educação Ambiental, institui a Política Nacional de Educação Ambiental e dá outras providências. Diário Oficial da República Federativa do Brasil. Brasília, n. 79, 28 abr. 1999.2 Disponível em: https://www.jusbrasil.com.br/diarios/DOU/1999/04/28. Acesso em: 8 maio 2019.

BRASIL. Ministério da Educação. Conselho Nacional de Educação. Resolução ํo 2, de 15 de junho de 2012. Estabelece as Diretrizes Curriculares Nacionais para a Educação Ambiental. Diário Oficial da União, Brasília, 18 jun. 2012. Seção $1 . \quad$ p. $70 . \quad$ Disponível em: https://www.jusbrasil.com.br/diarios/DOU/2012/06/18. Acesso em: 14 jul. 2019.

BRÜGGER, P. Educação ou adestramento ambiental. 3. ed. rev. e ampl. Florianópolis: Letras Contemporâneas, 2004. 197 p. 
CARVALHO, E.B.; CARMO, N.C.C.; HATAKEYAMA, R. Do Projeto Pedagógico à Prática: Um estudo sobre os egressos do curso de Ciências Socioambientais. In: LAS CASAS, E.B.; CUNHA, D.; QUEIROZ, T. (org.). UFMG Pesquisa Egressos. Belo Horizonte: Editora UFMG, 2019. p. 291-317. E-Book. Disponível em: https://www.editoraufmg.com.br/\#/pages/ebook/782. Acesso em: 4 fev. 2020.

CARVALHO, E.B.; FONSECA, C.R. Educação Ambiental no Ensino Superior Brasileiro: entre 0 adestramento $e$ a racionalidade ambiental. In: ESCHENHAGEN DURÁN, M.L.; LÓPEZ-PÉREZ, F. (org.). Ambientalización de la educación superior en América Latina: propuestas teóricas para su fundamentación. Medellin: UPB, 2016. p. 97-112.

CARVALHO, I.C.M.; MUHLE, R.P. Educação Ambiental: o problema das classificações e o cansaço de árvores. In: OLIVEIRA, Marcia Maria Dosciatti de et al. (org.). Cidadania, meio ambiente e sustentabilidade. Caxias do Sul, RS: Educs, 2017. p. 169-183.

ESCHENHAGEN DURÁN, M.L. Presentación. In: ESCHENHAGEN DURÁN, M.L.; LÓPEZ-PÉREZ, F. (org.). Ambientalización de la educación superior en América Latina: propuestas teóricas para su fundamentación. Medellin: UPB, 2016. p. 11-15.

GIL, A.C. Métodos e Técnicas de Pesquisa Social. 6. ed. São Paulo: Atlas, 2008. 248 p.

GUIMARÃES, S.S.M.; INFORSATO, E.C. A percepção de Biologia e sua formação em Educação Ambiental em questão. Ciência \& Educação, Bauru, v. 18, n. 3, p. 737-754, jan. 2012.

LAYRARGUES, P.P.; LIMA, G.F.C. As macrotendências político-pedagógicas da Educação Ambiental brasileira. Ambiente \& Sociedade, São Paulo, v. 17, n. 1, p. 23-40, jan./mar. 2014.

LEFF, E. Ambiente, interdisciplinariedad y currículum universitário: La educación superior en la perspectiva del desarrollo. In: El Curriculum de cara al nuevo milênio. México: CESU-UNAM, 1993. p. 22-28.

LEFF, E. Racionalidade ambiental: a reapropriação social da natureza. Rio de Janeiro: Civilização Brasileira, 2006. 555 p.

LEFF, E. Saber Ambiental. Petrópolis: Vozes, 2001. 343 p.

LOPES, T.M.; ZANCUL, M.C.S. A inclusão de temas ambientais nos cursos de Ciências Biológicas de universidades públicas paulistas. REMEA - Revista Eletrônica do Mestrado em Educação Ambiental, Rio Grande, v. 29. p. 1-16, jul./dez. 2012.

NICOLESCU, B. O manifesto da transdisciplinaridade. São Paulo: TRIOM, 1999. $185 \mathrm{p}$. 
PASE, J.; NORO, G.B.; MEDEIROS, F.S.B.; WEISE, A.D. Educação Ambiental na Universidade: Percepção dos Acadêmicos do Curso de Administração em Santa Maria - RS. Capital Científico, Guarapuava, v. 12, n. 2, p. 53-57, abr./jun. 2014.

REIGOTA, M. Meio ambiente e representação social. São Paulo: Cortez, 1995. $87 \mathrm{p}$.

ROMÃO, E.L.; BARGOS, D.C.; SILVA, L.A.G.; MELO, L.R. Percepção ambiental de alunos de graduação em engenharia sobre a importância da Educação Ambiental. Revista Brasileira de Educação Ambiental, Rio Grande, v. 15, n. 1, p. 194-208, 2020.

SÁ-SILVA, J.R.; ALMEIDA, C.D.; GUINDANI, J.F. Pesquisa documental: pistas teóricas e metodológicas. Revista Brasileira de História \& Ciências Sociais, Rio Grande, v. 1, p. 1-15, 2009.

SILVA, A.N.; WACHHOLZ, C.B.; CARVALHO, I.C.M. Ambientalização curricular: uma análise a partir das disciplinas ambientalmente orientadas na PUCRS. REMEA - Revista Eletrônica do Mestrado em Educação Ambiental, Rio Grande, v. 33, n. 2, p. 209-226, 2016.

SOUZA, P.V.T.; AMAURO, N.Q.; PAULA, A.G.; RODRIGUES FILHO, G. A Educação Ambiental nas aulas de química do Ensino Superior: resultados de uma investigação realizada em uma universidade pública brasileira. In: CONGRESO INTERNACIONAL SOBRE INVESTIGACIÓN EN DIDÁCTICA DE LAS CIENCIAS, 10., 2017, Sevilha. Anais [...]. Sevilha, 2017. p. 3455-3460. Disponível em: https://core.ac.uk/download/pdf/147043013.pdf. Acesso em: 7 maio 2019.

SOUZA, V.M. Uma discussão sobre a inserção do Meio Ambiente no curriculum dos cursos "ambientais" em Universidades Públicas do Estado do Rio de Janeiro. 2011. 202 f. Dissertação (Mestrado em Ciências Ambientais) Universidade Federal Fluminense, Niterói, 2011.

THOMAZ, C.E.; CAMARGO, D.M.P. Educação Ambiental no Ensino Superior: múltiplos olhares. REMEA - Revista Eletrônica do Mestrado em Educação Ambiental, Rio Grande, v. 18, p. 1-18, jan./jun. 2007.

UFMG. Plano de Desenvolvimento Institucional 2018-2023. Belo Horizonte, 2018. 372 p.

UFMG. Projeto Pedagógico do Curso de Graduação em Ciências Socioambientais. Belo Horizonte, 2012. 71 p.

VEIGA, R.C.A.; NUNES, M.L.R.L.; RODRIGUES, M.A.; XIMENES, V.L. A temática Meio Ambiente no Ensino Superior em uma instituição localizada em Teresina - Piauí. Holos, Teresina, v. 2, p. 206-215, maio. 2013. 